\title{
Effects of prompting, confirmation, and free choice upon children's acquisition, verbalization and generalization of a concept
}

\author{
WILLIAM G. Le FURGY and JAMES A. SISSERSON, Princeton \\ University, Princeton, N. J. 08540
}

Thirty superior 13-year-old girls were confronted with a concept attainment task under conditions of preresponse prompting, postresponse confirmation, or a fi se choice condition in which the $S$, on each trial, could elect tu have her responses prompted or confirmed. Results indicated no significant differences between these conditions during acquisition. However, free choice Ss evidenced significantly greater ability for both verbalization of the concept and generalization of the rule to a second set of stimuli. Free choice Ss tended to elect prompts as a decreasing function of trials.

The past decade of research in human learning has seen an increasing interest in the events that preceed the learner's response. By introducing a variety of response guiding techniques, numerous studies have exploited the human capacity for directed attention to relevant aspects of the task. There is a growing and controversial literature concerning the relative efficacy of procedures which inhibit the $S$ from making incorrect responses by prompting him to respond correctly. This, in contrast to the more traditional response-contingent procedures that offer confirmation, or reinforcement, only after the $\mathrm{S}$ has performed the response. Aiken \& Lau (1967) have reviewed the literature on this issue and have found a mixed pattern of results with regard to the relative effectiveness of prompting and confirmation procedures. The superiority of one procedure over the other was found to vary with the nature of the task and the chronological and mental age of the Ss. Confirmation procedures were found to offer no consistent advantages over prompting methods across tasks involving verbal learning, perceptual learning, and signal monitoring. One consistent finding has been that prompting is most effective when it occurs early in the learning process (Cook \& Kendler, 1956; Hawker, 1964a, 1964b, 1965a, 1965b; Kopstein \& Roshal, 1961). A number of investigators (Angell \& Lumsdaine, 1960; Stolurow, 1961; Stolurow \& Lippert, 1964) have found that a combination of prompting and confirmation procedures is the most effective in paired-associate learning. In one of the few studies to deal with the problem of transfer, Cook \& Miller (1963) found no differential effects of prompting and confirmation on a problem solving task. Their study indicated that prompting may interfere with learning when the task requires the internal chaining of enactive or motor responses.

There is an absence of studies designed to assess the roles of prompting and confirmation in tasks which require the learning of complex relationships between multidimensional stimuli. Evidence is lacking concerning the impact of response guidance procedures upon the attainment and generalization of verbally mediated concepts. It could be predicted that response confirmation would be well suited to the systematic testing of hypotheses in a rule learning task. Conversely, prompting with preresponse information might well interfere with the S's formation and testing of hypotheses. Because of this influence upon hypothesis testing, prompting and confirmation procedures may well have a differential influence upon the S's ability to verbalize and hence generalize the concept after it has been attained. The present experiment was designed to assess the effects of three different conditions of acquisition upon children's attainment and usage of a relational rule.

\section{SUBJECTS}

Thirty upper-middle class children served as Ss in the study. All of the Ss were female and comprised a single sixth-grade class at a private day school in Princeton, New Jersey. Their mean, Kuhlmann-Anderson, IQ was 123 , (SD $=15.5)$. Ten children were assigned at random to each of the three experimental groups.

\section{STIMULUS MATERIALS}

The concept was displayed to the Ss through a sequence of 240 , 7 in. $x 14$ in., randomly ordered cards. On each card there were three different, irregular figures. Six different figures, with 4, 5, 6, 7,8 , or 10 sides were used during the acquisition phase. Each of the figures on every card was either yellow, black, or hatched. On any given card a figure could vary with regard to: position (left, right, or center), color, or number of sides.

A second deck of 12 cards was used to test for the S's generalization of the concept. These cards were 15 in. $x 20$ in. and they each displayed three different irregular figures. These generalization figures had the same number of sides as the acquisition figures but were different from them in shape. The figures on each card were colored either red, green, or gold. On half of the cards the three figures were arranged diagonally. On the remaining cards the three figures were oriented horizontally.

During both acquisition and generalization trials the stimulus cards were displayed on a rectangular box 4 in. $x 10$ in. $x 20$ in. placed lengthwise on a table between the $S$ and the $E$. The $S$ was faced with three response buttons and three lights, spaced to coincide with the three figures on the stimulus cards. The $E$ had three buttons which controlled the lights in front of the S. The S's buttons were disconnected and were employed to provide a rationale for the $\mathrm{S}$ making a discrete response on each trial.

$$
\text { PROCEDURE }
$$

The $E$ and the $S$ were seated facing each other across the response box. The stimulus cards were displayed to the $S$ in a fixed random sequence. The $S$ was instructed that on each card only one of the figures was "correct." Her task was to discover the rule that would allow her to tell which of the three figures on each card was correct. The Ss were informed that the same figure could be "right" on one card and "wrong" on the next. The relational concept of the figure with the most sides was the rule to be learned. The odd-numbered trials were acquisition trials, on which the Ss were given information as to which of the three figures was correct. The even-numbered cards in the sequence were used as test trials on which the $\mathrm{S}$ was given no information.

The Ss were randomly assigned to three treatment groups of 10 Ss each. In the prompting procedure, a light was lit in front of the correct figure on each card as it was placed before the $S$. The $S$ was allowed to study the card for as long as she wished. She indicated to the $\mathrm{E}$ that she was ready to proceed by pressing the button that corresponded to the correct figure. In the confirmation procedure, the $S$ was required to push the button in front of the figure that she thought to be correct. If the response was correct, the corresponding light went on. The S was allowed to study the card and push the button again when she was ready to proceed. If she made an incorrect response, no light went on. In the free choice condition, the $\mathrm{S}$ was instructed as in both the prompting and confirmation procedures. She was then given the option, on each acquisition trial, to choose between the two.

Criterion performance was seven consecutively correct test trials. Upon reaching criterion, the $\mathrm{S}$ was shown the 12 generalization cards. She was then asked to indicate the "correct" figure on each of these cards by using the same rule that she had learned on the previous cards. The Ss were then asked to verbalize the rule that they had been following.

\section{RESULTS}

Of the $30 \mathrm{Ss}, 22$ reached the criterion of seven consecutively correct test trials. Eight Ss reached criterion in the prompting condition, six in confirmation, and eight in free choice. The Ss who failed to reach criterion were not considered in the analyses of the data. Analyses of the Ss' performance during the acquisition phase of the study with regard to the number of Ss reaching criterion, and the number of errors, time, or trials to criterion, revealed no statistically reliable differences between the three 


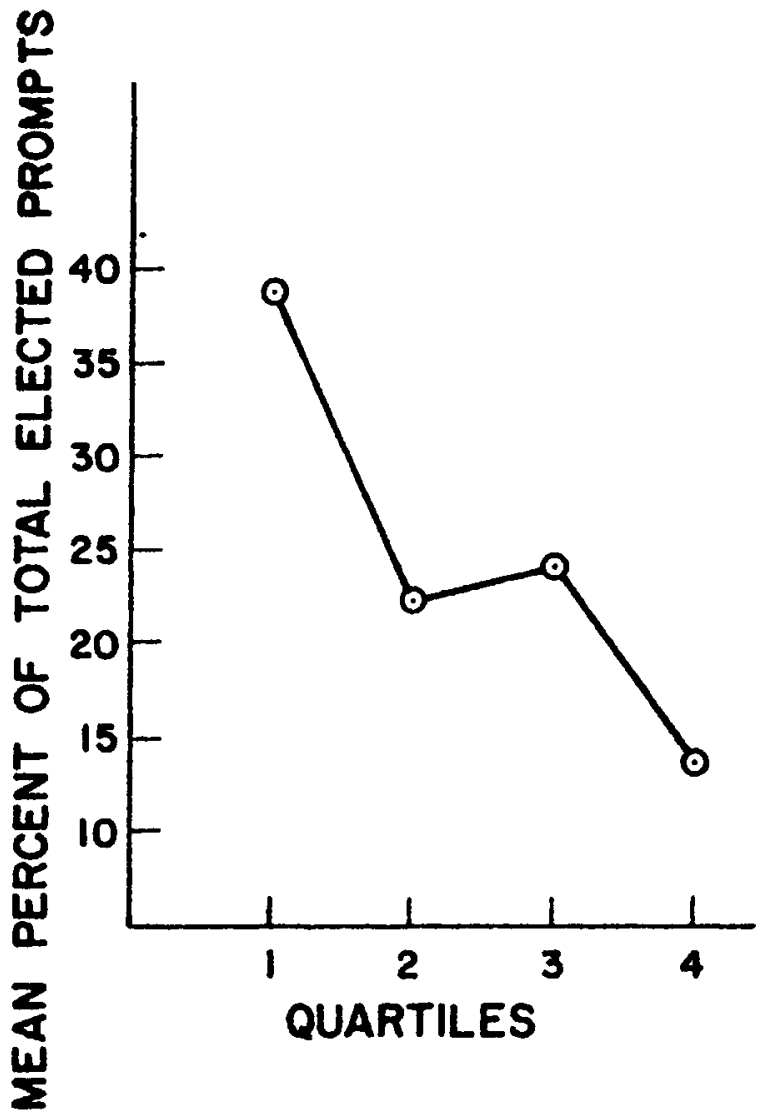

Fig. 1. Mean per cent of total elected prompts per quartile of trials to criterion for $\mathrm{Ss}$ in the free-choice condition.

experimental treatments. However, after they had achieved a criterion performance, statistically significant differences were found across the three treatment conditions in the Ss' final capacities to verbalize and to generalize the concept. Only $17 \%$ of the confirmation $\mathrm{Ss}$, reaching criterion, were able to verbalize the rule correctly. To be labeled correct, a verbalization had to contain information to the effect that: "the figure with the most sides is correct." Two independent judges categorized the Ss' verbalizations with $100 \%$ agreement. Fifty per cent of the prompted Ss successfully verbalized the rule, while $88 \%$ of the Ss in the free choice condition verbalized the rule correctly. A chi square test shows these differences in frequency of verbalization over the three acquisition procedures to be significant at the .02 level $\left(X^{2}=7.04, d f=2\right)$. Fisher exact probabilities of the multiple comparisons among the treatments are as follows: prompting vs confirmation, $p=.21$; free choice vs prompting, $p=.13$; free choice vs confirmation, $\mathrm{p}=.01$.

In addition to verbalizing the rule more frequently, the $S s$ in the free choice condition evidenced a superior ability for generalizing the rule to a new set of stimuli. The median number of correct generalizations, out of a possible 12, for each treatment was: 9 for prompting, 8 for confirmation, and 11 for free choice. A Kruskal-Wallis one-way analysis ' of variance showed these differences to be significant with $p<.01$. A multiple comparison procedure, using the Mann-Whitney $U$ test, yielded the following two-tailed levels of significance: prompting vs confirmation, not significant: free choice vs prompting, $\mathrm{p}<.02$; free choice vs confirmution, $\mathrm{p}<.01$. A point biserial correlation between S's ability to verbalize and to generalize the rule was .79 . The relationships between I.Q. and verbalization and I.Q. and generalization did not approach significance.

The $\mathrm{Ss}$ in the free-choice condition elected prompts on an average of $45 \%$ of their acquisition trials. Fig. 1 displays the mean per cent of total elected prompts per quartile of trials to criterion for all of the $S s$ who reached criterion in the free-choice condition.

Figure 1 indicates that the $S s$ in the free-choice condition tended to administer to themselves a schedule of prompts and confirmation that is comparable to standard "vanishing" procedures such as those employed by Angell \& Lumsdaine (1960), and Stolurow \& Lippert (1962).

The circumstances of free-choice, while not necessarily facilitating concept attainment, do appear to have important implications for concept usage. A confirmation procedure forces the $S$ to rely upon his own resources for the generation of hypotheses. A prompting procedure allows for the generation of multiple hypotheses, but with only a minimum of opportunity to test them. By allowing the $S$ to determine his own schedule of information, the free-choice procedure permits the $S$ to explore the validity of a hypothesis over a sequence of trials. As these hypotheses fail, the $\mathrm{S}$ may return to a prompting procedure for assistance in the generation of new hypotheses. The net effect of such an alternation strategy is to promote verbalization of the rule and greater accuracy in subsequent attempts at generalization. Further research is required to determine if such alternation strategies are in fact characteristic of free choice procedures.

The present study indicates that the conditions surrounding children's attainment of rules seem less related to speed of acquisition than they do to the effectiveness with which the rule is applied after it has been attained. Further studies are in progress to determine if these relationships hold for children with average and below average verbal skills.

\section{REFERENCES}

AIKEN, E. G., \& LAU, A. W. Response prompting and response confirmation: A review of recent literature. Psychological Bulletin, 1967, $68,330-341$.

ANGEL, D., \& LUMSDAINE, A. A. Prompted plus unprompted trials vs prompted trials alone in paired-associate learning. USAF Office of Scientific Research Technical Note, 1960, No. 60-808, 19.

COOK, J. O., \& KENDLER, T. S. A theoretical model to explain some paired-associate learning data. In G. Finch \& F. Cameron (Eds.), Symposium on Air Force human engineering, personnel and training research. (Publ. No. 455) Washington, D. C. National Research Council, 1956. Pp. $90-98$.

COOK, J. O., \& MILLER, H. G. Studies in guided learning. Cooperative Research Project No. 1242, 1963, University of North Carolina.

HAWKER, J. R. Effects of prompting and confirmation in a serial learning task. Journal of Experimental Psychology, 1964a, 67, 99-101.

HAWKER, J. R. The influence of training procedure and other task variables in paired-associate learning. Journal of Verbal Learning \& Verbal Behavior, $1964 b, 3,70-76$.

HAWKER, J. R. The effects of training procedure, response availability, and response meaningfulness in multiple-choice, paired-associate learning. Psychonomic Science, 1965a, 3, 329-330.

HAWKER, J. R. The effects of training procedure, response similarity, and number of response alternatives in multiple-choice, paired-associate learning. Psychonomic Science, 1965b, 3, 331-332.

STOLUROW, L. M. Teaching by machine. Cooperative Research Monograph No. 6. U.S. Department of Health, Education and Welfare, Washington, D.C. U.S. Government Printing Office, 1961. 